\title{
Mitochondria in White, Brown, and Beige Adipocytes
}

\author{
Miroslava Cedikova, ${ }^{1,2}$ Michaela Kripnerová, ${ }^{3}$ Jana Dvorakova, ${ }^{4}$ Pavel Pitule, ${ }^{2,5}$ \\ Martina Grundmanova, ${ }^{1,2}$ Vaclav Babuska, ${ }^{6}$ Dana Mullerova, ${ }^{4}$ and Jitka Kuncova ${ }^{1,2}$ \\ ${ }^{1}$ Department of Physiology, Faculty of Medicine in Pilsen, Charles University in Prague, 30100 Pilsen, Czech Republic \\ ${ }^{2}$ Biomedical Centre, Faculty of Medicine in Pilsen, Charles University in Prague, 30100 Pilsen, Czech Republic \\ ${ }^{3}$ Department of Biology, Faculty of Medicine in Pilsen, Charles University in Prague, 30100 Pilsen, Czech Republic \\ ${ }^{4}$ Department of Public Health and Preventive Medicine, Faculty of Medicine in Pilsen, Charles University in Prague, \\ 30100 Pilsen, Czech Republic \\ ${ }^{5}$ Department of Histology and Embryology, Faculty of Medicine in Pilsen, Charles University in Prague, 30100 Pilsen, Czech Republic \\ ${ }^{6}$ Institute of Medical Chemistry and Biochemistry, Faculty of Medicine in Pilsen, Charles University in Prague, \\ 30100 Pilsen, Czech Republic
}

Correspondence should be addressed to Jitka Kuncova; jitka.kuncova@lfp.cuni.cz

Received 31 July 2015; Revised 17 January 2016; Accepted 28 January 2016

Academic Editor: Norbert Pallua

Copyright (C) 2016 Miroslava Cedikova et al. This is an open access article distributed under the Creative Commons Attribution License, which permits unrestricted use, distribution, and reproduction in any medium, provided the original work is properly cited.

\begin{abstract}
Mitochondria play a key role in energy metabolism in many tissues, including cardiac and skeletal muscle, brain, liver, and adipose tissue. Three types of adipose depots can be identified in mammals, commonly classified according to their colour appearance: the white (WAT), the brown (BAT), and the beige/brite/brown-like (bAT) adipose tissues. WAT is mainly involved in the storage and mobilization of energy and BAT is predominantly responsible for nonshivering thermogenesis. Recent data suggest that adipocyte mitochondria might play an important role in the development of obesity through defects in mitochondrial lipogenesis and lipolysis, regulation of adipocyte differentiation, apoptosis, production of oxygen radicals, efficiency of oxidative phosphorylation, and regulation of conversion of white adipocytes into brown-like adipocytes. This review summarizes the main characteristics of each adipose tissue subtype and describes morphological and functional modifications focusing on mitochondria and their activity in healthy and unhealthy adipocytes.
\end{abstract}

\section{Introduction}

Over the past few decades, the number of studies in the field of adipose tissue biology has increased exponentially since obesity and associated diseases are occurring at epidemic rates not only in developed countries, but also in developing countries. Obesity arises from an imbalance between energy intake and expenditure. It is associated with an increased risk of type 2 diabetes, hypertension, atherosclerosis, heart disease, stroke, cancer, infertility, and so forth [1-5]. Current clinical approaches to obesity include diet, physical activity, psychological support, drugs, and surgery treatment. Unfortunately, these treatment methods show efficiency limited only to small percentage of patients and some of them may be accompanied by serious side effects.
Studies published over the last two decades have established adipose tissue as a dynamic organ that carries out several important physiological processes. It is composed of a number of cell types: adipocytes, preadipocytes, vascular endothelial cells, pericytes, macrophages, and fibroblasts [6]. However, the dominant cells present in adipose tissue are mature adipocytes.

Two major types of adipose tissue exist in mammals, brown and white fat that have essentially antagonistic functions, brown fat expending energy and white fat storing it [7]. Brown adipocytes may occur after thermogenic stimulation at anatomical sites corresponding to WAT. This process is called the "browning" of WAT and these brown-like adipocytes that appear in WAT are called "beige" or "brite" $[8,9]$. These three types of adipose cells have many specific 
characteristics related to localization, cell composition (lipid droplet, mitochondria), function, pathways of homeostatic control, obesity related changes, and so forth $[8,10]$.

Recent data suggest that adipocyte mitochondria might play an important role in the development of obesity through defects in mitochondrial lipogenesis and lipolysis, regulation of adipocyte differentiation, apoptosis, production of oxygen radicals, efficiency of oxidative phosphorylation, and regulation of conversion of white adipocytes into brown-like adipocytes [11, 12]. Thus, therapeutic intervention into any of these mitochondrial processes could be a useful approach to reduce adiposity [13].

This review summarizes the main characteristics of each adipose tissue subtype and describes morphological and functional modifications focusing on mitochondria and their activity in healthy and unhealthy adipocytes.

\section{Overview of Mitochondrial Functions}

Mitochondria are the cytoplasmic organelles in human and animal cells where many distinct metabolic pathways take place [14]. Mitochondria are highly dynamic, pleomorphic organelles comprising at least six compartments: outer membrane, inner boundary membrane of significantly larger surface area, intermembrane space, cristal membranes, intracristal space, and protein rich matrix. They are found in almost all human cells except mature erythrocytes $[15,16]$. Although mitochondria contain their own small mtDNA and some RNA components of mitochondrial translational apparatus, the vast majority of the mitochondrial proteins are encoded by nuclear DNA, synthesized in the cytosol, and then imported into the mitochondria posttranscriptionally [15]. Mitochondria are involved in the crucial metabolic processes including tricarboxylic acid cycle, pyruvate decarboxylation, oxidative decarboxylation of fatty acids ( $\beta$-oxidation), and degradation of branched amino acids. Mitochondria also substantially contribute to biosynthetic processes taking place in the cytosol by providing key intermediates like urea cycle, fatty acids, and heme synthesis. However, the principal role of mitochondria is to synthesize more than 95\% of adenosine triphosphate (ATP) for cellular utilization $[14,16]$. Production of ATP requires two major steps, oxidation of highly reducing metabolites and coenzymes such as nicotinamide adenine dinucleotide (NADH) and flavin adenine dinucleotide $\left(\mathrm{FADH}_{2}\right)$ and phosphorylation of adenosine diphosphate to generate ATP to support various cellular functions (OXPHOS, oxidative phosphorylation) [17]. The mitochondrial respiratory system consists of four enzymatic multiheteromeric complexes (I-IV) embedded in the inner membrane of mitochondria and two individual mobile molecules, coenzyme Q (CoQ) and cytochrome $c$, along which the electrons liberated by the oxidation of $\mathrm{NADH}$ and $\mathrm{FADH}_{2}$ are passed and ultimately transferred to molecular oxygen. This respiratory process creates the electrochemical gradient of protons and membrane potential about $180 \mathrm{mV}$ across the inner membrane that has the potential to do work. The proton flux drives the $\mathrm{F}_{0} \mathrm{~F}_{1}$ ATP synthase (complex V) to phosphorylate matrix ADP by inorganic phosphate $[18,19]$. On the other hand, mitochondria

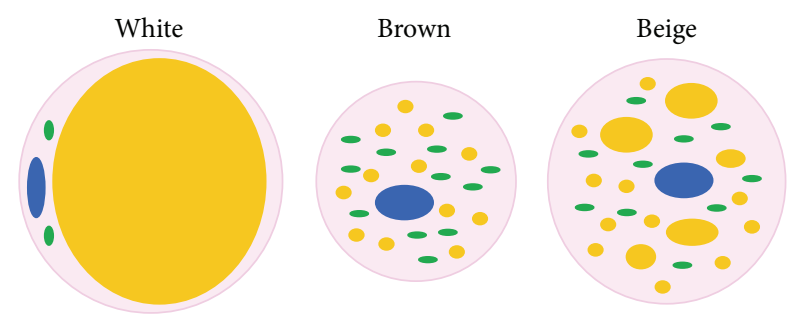

FIGURE 1: Main morphological characteristics of white, brown, and beige adipose tissues. White adipocyte cell is classically spherical, it is full of single lipid droplet, and it contains few mitochondria. Brown adipocyte is usually smaller than white and beige ones. It contains a large number of mitochondria and contains multiple small lipid droplets. Blue: nucleus, green: mitochondria, and yellow: lipid droplets.

generate heat by a mechanism called "proton leak." Protons leak from the intermembrane space to matrix and reduce membrane potential generating heat instead of energy [17]. Mitochondria are also deeply involved in the production of reactive oxygen species (ROS) through electron carriers in the respiratory chain. Oxidative stress can induce apoptotic death and mitochondria have a central role in this process due to cytochrome $c$ release in the cytoplasm and opening of the permeability transition pore [20,21]. Mitochondria are essential for the maintenance of normal physiological function of tissue cells and mitochondrial dysfunction may cause pathological changes in the human body [14]. In addition, eukaryotic cells have the ability to initiate adaptive responses to different environmental stimuli (e.g., cell growth, death and differentiation, or modification in energy demands) by altering the number, morphology, or remodelling of mitochondria [11].

\section{White versus Brown versus Beige Adipocyte Tissue}

In mammals, we can find three types of adipose depots commonly classified according to their colour appearance: the white (WAT), the brown (BAT), and the beige/brite/brownlike (bAT) adipose tissues. Main characteristics of WAT, BAT, and bAT in humans are shown in Table 1 and main morphological differences are shown in Figure 1. Most mammals have WAT dispersed throughout the body in two major types of depots, subcutaneous and intra-abdominal (or visceral). Intra-abdominal fat includes retroperitoneal, omental, mesenteric, epicardial, and gonadal deposits. WAT weight generally represents as much as $20 \%$ of the body weight of normal adult human and primarily acts as a storage site for triglycerides, conserving excess calories for use in times of scarcity. White adipocytes contribute to the whole body insulation and have endocrine functions including secretion of leptin, TNF- $\alpha$, adiponectin, resistin, and other compounds related to the degree of obesity and insulin sensitivity [22].

Humans have relatively large depots of BAT in infancy; only small amounts of BAT dispersed throughout the depots 
TABLE 1: Main differences amongst the three types of adipocyte tissue.

\begin{tabular}{|c|c|c|c|c|}
\hline Characteristic property & White & Brown & Beige & References \\
\hline \multicolumn{5}{|l|}{ Morphology } \\
\hline (i) Shape & Spherical & Ellipsoid/polygonal & Spherical & \multirow{4}{*}[8,9,23]{} \\
\hline (ii) Cell size & Variable, large $(25-200 \mu \mathrm{m})$ & Small $(15-60 \mu \mathrm{m})$ & Variable, smaller than white & \\
\hline (iii) Lipid droplet (LD) & Single large LD & Multiple small LD & Multiple LD with variable size & \\
\hline (iv) Mitochondria & + & +++ & ++ (upon stimulation) & \\
\hline Development & $\begin{array}{l}\text { From Myf5 } 5^{-} \text {or } \mathrm{Myf5}^{+} \\
\text {precursors }\end{array}$ & $\begin{array}{l}\text { From Myf5 } \\
\text { precursors }\end{array}$ & $\begin{array}{l}\text { From Myf5 } 5^{-} \text {or } \mathrm{Myf5}^{+} \\
\text {precursors }\end{array}$ & {$[23-26]$} \\
\hline Location & Subcutaneous and visceral & $\begin{array}{l}\text { Suprarenal, } \\
\text { paravertebral, } \\
\text { supraclavicular }\end{array}$ & $\begin{array}{l}\text { Inguinal, neck (near carotid } \\
\text { sheath and musculus longus } \\
\text { colli), other locations? }\end{array}$ & {$[8,27]$} \\
\hline Function & Energy storage & Heat production & Adaptive thermogenesis & [9] \\
\hline Uncoupling protein & Nearly undetectable & +++ & ++ (upon stimulation) & {$[28,29]$} \\
\hline $\begin{array}{l}\text { Adipocyte-type-specific } \\
\text { markers }\end{array}$ & $\begin{array}{l}\text { PPAR }, \text { PLIN1, HOXC9, } \\
\text { TCF21, TLE3, C/EBP } \alpha, R b, \\
\text { Rip140 }\end{array}$ & $\begin{array}{l}\text { LHX8, ZIC1, EPSTI1, } \\
\text { PRDM16, CIDEA, } \\
\text { ELOVL3 }\end{array}$ & $\begin{array}{l}\text { HOXC8, HOXC9, CITED1, } \\
\text { CD137, TMEM26, TBX1, CD40 }\end{array}$ & {$[13,23,30,31]$} \\
\hline Vascularization & Low & High & High upon stimulation & {$[32,33]$} \\
\hline Impact on obesity & Positive & Negative & Negative & {$[34]$} \\
\hline $\begin{array}{l}\text { Correlation with insulin } \\
\text { resistance }\end{array}$ & Yes & Probably yes & Probably yes & [35-38] \\
\hline
\end{tabular}

CD40: CD40 molecule, TNF receptor superfamily member 5; CD137: tumour necrosis factor receptor superfamily, member 9; C/EBP $\alpha$ : CCAAT/enhancer binding protein (C/EBP), alpha; CIDEA: cell death-inducing DFFA-like effector; CITED1: Cbp/p300-interacting transactivator, with Glu/Asp-rich carboxyterminal domain 1; ELOVL3: ELOVL fatty acid elongase 3; EPSTI1: epithelial stromal interaction 1; HOXC8: homeobox C8; HOXC9: homeobox C9; LHX8: LIM homeobox protein 8; PLIN1: perilipin-1; PPAR $\gamma$ : peroxisome proliferator-activated receptor gamma; PRDM16: PR domain containing 16; Rb (Rb1): retinoblastoma 1; Rip140: nuclear receptor interacting protein 1; TBX1: T-Box 1; TCF21: transcription factor 21; TLE3: transducin-like enhancer of split 3; TMEM26: transmembrane protein 26; ZIC1: zinc finger protein of the cerebellum 1.

of WAT persist in adults. Classical brown fat is primarily distributed in the interscapular space, paravertebrally, axillary, and perirenally. Recent studies have confirmed the presence of active BAT containing both classical brown and beige adipocytes in adult humans, with depots residing in the cervical, supraclavicular, mediastinal, paravertebral, and suprarenal regions $[27,39,40]$.

White adipocyte cell is classically spherical and large with flattened nucleus, which is situated in the periphery. Because it is nearly completely filled with a single lipid droplet, thin ring of cytoplasm contains few mitochondria and little but recognizable smooth endoplasmic reticulum [41]. Brown adipocyte is usually smaller than the white one and its shape is elliptical with round or oval nucleus situated centrally. Cytoplasm volume is large containing multiple small lipid droplets, poor endoplasmic reticulum, and high amount of mitochondria.

Beige adipocyte has the mixed characteristics of both white and brown adipose cells. During basal state, it displays unilocular morphology as white adipocyte, but, upon cold stimulation, its appearance acquires features of intermediate morphology ultimately resulting in expression of proteins typical for BAT and transformation of stored fat into the small lipid droplets typical for brown adipocytes [8, 42, 43]. The origin and function of beige adipocytes are less clear and currently under intense discussion. It is thought that they arise from unique precursor cells [42], but there is also evidence that they stem from white adipocytes by transdifferentiation of preexisting white adipocytes. HimmsHagen et al. treated rats with $\beta 3$-adrenoceptor agonist (CL316243); the results of their study showed that at least a subpopulation of unilocular adipocytes underwent conversion to multilocular mitochondria-rich adipocytes [44]. Interestingly, Morroni and coworkers suggested a new mechanism of reversible physiological transdifferentiation of adipocytes in the mammary gland: mouse mammary adipocytes are able to transform into secretory epithelial cells during pregnancy and revert to adipocytes after lactation [45]. Moreover, recent research has shown novel mechanism of the bAT formation. Wang et al. suggested that during cold-induced "browning" of subcutaneous fat, most "beige" adipose cells stem from de novo differentiated adipocytes [46]. Vargas et al. found that adipocytes differentiated with total and partial agonists of peroxisome proliferator-activated receptor gamma (PPAR $\gamma)$ and exposed to $31^{\circ} \mathrm{C}$ are able to respond to cold by a significant increase in the expression of thermogenic proteins such as uncoupling protein 1 (UCP1), peroxisome proliferator-activated receptor c coactivator 1 (PGCl $\alpha$ ), and $\mathrm{Cbp} / \mathrm{p} 300$-interacting transactivator, with Glu/Asp-rich carboxy-terminal domain 1 (CITED1), a marker of the beige phenotype [28]. Two potential models of mature WAT into bAT transformation are shown in Figure 2.

Interestingly, exercise has been recently considered as a physiological stimulus for brown adipose tissue activity [47]. Even vibration training changed lipid metabolism in rats and promoted brown fat-like modifications in white adipose 


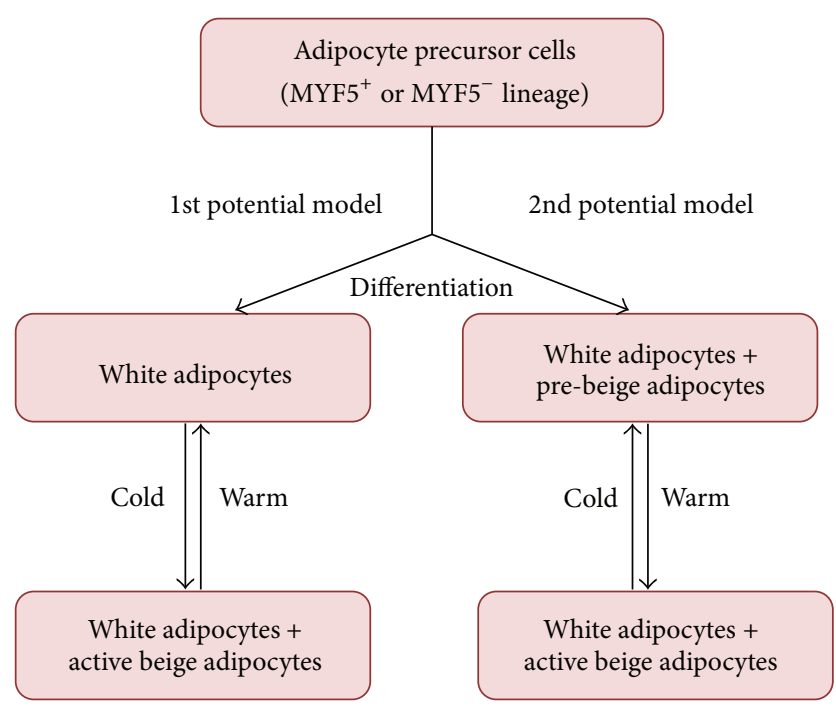

FIGURE 2: Two potential models of how WAT can be transformed into beige adipocytes $[23,25,26]$.

tissues through triggering BAT-associated gene expression, inflammatory response, and decrease in energy reserve [48]. Understanding these biological processes and stimulation of the activity of brown and beige/brite adipocytes could help us with fight against obesity, potentially facilitate weight loss, and improve metabolic health [49].

\section{Mitochondrial Activity in Adipocytes}

Mitochondria play a central role in metabolism of adipose tissue, as documented by their contribution to metabolic pathways of particular importance in adipocytes, like lipolysis and lipogenesis [11]. In addition, specific function performed by brown fat is converting mitochondrial energy into heat in adaptive thermogenesis. Tissue-specific functions of mitochondria in white fat are less characterized [50], although their role in orchestrating metabolic homeostasis and weight control is now widely accepted [51].

Lipolysis in adipocytes is the hydrolysis of triglycerides from lipid droplets within the cell into glycerol and free fatty acids by hormone-sensitive lipase (HSL) and adipose triglyceride lipase (ATGL). The hydrolytic action of HSL is regulated by perilipin A, a lipid droplet-associated protein. Phosphorylation of perilipin A by cAMP-dependent protein kinase (PKA) facilitates the translocation of HSL into the lipid droplet [52]. In the cytoplasm, free fatty acids are presumably bound to binding proteins and subsequently moved across the inner mitochondrial membrane by diffusion or, in the case of long carbon chains, by the carnitine shuttle $[39,53]$. B-oxidation, metabolic process breaking down free fatty acids into acetyl-CoA takes place in the mitochondrial matrix. Acetyl-CoA then undergoes oxidation through the tricarboxylic acid cycle and the electron transport system.

The lipogenesis de novo is an important pathway to convert fatty acids to triglycerides for storage in the WAT. The human liver is mainly responsible for the conversion of carbohydrates into fatty acids, but a small part of triglycerides is synthesized in adipocytes [52]. Although fatty acids and triglycerides synthesis take place in the cytosol, mitochondria provide key intermediates needed for lipogenesis, like glycerol 3-phosphate and acetyl-CoA. Key enzyme in glycerol 3 -phosphate synthesis is mitochondrial pyruvate carboxylase that converts pyruvate into oxaloacetate. Pyruvate also undergoes decarboxylation to acetyl-CoA by the mitochondrial pyruvate dehydrogenase complex, which facilitates fatty acid and triglyceride synthesis [54].

As mentioned above, brown/beige adipocytes, when activated by sympathetic stimulation, dissipate chemical energy stored in the form of triglycerides by channelling fatty acids into $\beta$-oxidation. Energy of substrate oxidation is then converted into heat $[49,55,56]$. This process, termed nonshivering thermogenesis, is specific function of BAT/bAT and is particularly important during hibernation and for small animals and infants who have greater demands on thermogenesis due to a large surface-to-volume ratio [57]. The molecular substrate of this unique function is a protein containing three similar repeats of about 100 amino acids coded by nuclear genes and inserted into the inner mitochondrial membrane [58]. As the major role of the protein is proton translocation resulting in uncoupling of the electrontransporting system from ATP synthesis in the mitochondria, it was named uncoupling protein (UCP) [59].

Uncoupling proteins belong to a family of mitochondrial carrier proteins that are present in the mitochondrial inner membrane. Mammals express five UCP homologues (UCP1 also named thermogenin), UCP2, UCP3, UCP4, and UCP5, also known as brain mitochondrial carrier protein 1 (BMCP1) [60]. UCP1 is expressed almost exclusively in fully differentiated BAT cells [17], although some findings suggest that UCP1 can be detected also in other tissues including uterine smooth muscle and even WAT, where induction of uncoupling protein expression is associated with acquiring of brown fat features $[61,62]$. Expression of UCP1 in WAT has been questioned by finding of brown adipocytes in white depots and white adipocytes that potentially could transdifferentiate into cells expressing markers of BAT/bAT after appropriate stimulation [56, 62]. UCP2 and UCP3 mRNAs have been detected in a number of tissues and organs, for example, thymus, stomach, testis, white and brown adipocytes, pancreatic $\beta$-cells (UCP2) and skeletal muscle, heart, and brown adipocytes (UCP3) [63-67]. The physiological function of UCP1 is to mediate a regulated proton leak and thus dissipate the proton electrochemical gradient built up by the respiratory chain in the form of heat. Maximally stimulated brown adipose tissue can produce about $300 \mathrm{~W} / \mathrm{kg}$ of heat compared to $1 \mathrm{~W} / \mathrm{kg}$ in all other tissues $[29,68]$. The thermogenesis in BAT is induced and positively regulated by fatty acids; in fact, no heat generation can be elicited without simultaneously initiating lipolysis. Further oxidation of acetyl-CoA the end product of $\beta$ oxidation, through tricarboxylic acid cycle and the electron transport chain, provides energy dissipated as heat through the action of UCP1 [69]. In contrast to UCP1, physiological function of its homologues is still debated. Recent studies 
have shown that UCPs might have an important role in pathogenesis of various disorders as type 2 diabetes, obesity, heart failure, neurodegenerative diseases, aging, or tumorigenesis [70-75].

Metabolic differences between mitochondria of WAT and BAT are associated with specific morphological characteristic of mitochondria in the brown adipocytes. These mitochondria are apparently more numerous and bigger in size and contain more cristae than mitochondria in white adipocytes. In addition, content of the heme cofactors in the mitochondrial enzyme cytochrome oxidase gives the tissue the brown macroscopic colour $[16,76]$. Compared to BAT, WAT has fewer mitochondria, mostly undetectable expression of UCP1, and lower expression levels of the fatty acid $\beta$-oxidation-related enzyme, acyl CoA dehydrogenase, suggesting that the intensity of $\beta$-oxidation in WAT is lower than in BAT $[53,56,77,78]$. As in other tissues, mitochondria represent the main source of ATP in the white fat. White fat mitochondria are well equipped for oxidative phosphorylation, with pyruvate serving as a main source of energy for ATP synthesis. Due to low activity of carnitine palmitoyltransferase 1 in the inner mitochondrial membrane, oxidation of fatty acids is relatively slow and fatty acids are directed towards esterification, unless the transferase is activated by leptin [79].

Forner et al. reported a systematic analysis of mouse mitochondrial proteomes of brown and white adipocytes documenting significant differences in the two sets of proteins, both qualitative and quantitative. Acetyl-CoA synthetase 2-like (gene Acss1), converting acetate to acetyl-CoA, and pyruvate dehydrogenase kinase 4 (gene $P d k 4$ ), inhibiting the pyruvate dehydrogenase complex thereby reducing the conversion of pyruvate to acetyl-CoA, were detected only in BAT. Conversely, MOSC domain-containing protein 1 (gene Mosc1), component of prodrug-converting complex, and acyl-coenzyme A synthetase ACSM5 (gene Acsm5), having CoA ligase activity, were detected only in WAT [50]. At transcript and proteome levels, BAT mitochondria were more similar to their counterparts in muscle cells. In contrast, WAT mitochondria not only selectively expressed proteins that support anabolic lipogenic function but also degrade xenobiotics and endogenous molecules, revealing a protective role of this tissue. These observations might help in better understanding of physiological processes in adipose tissue [50].

During adipocyte differentiation, the appropriate function of mitochondrion-specific metabolic processes is essential [11]. Adipogenic differentiation is characterized by the enhanced expression of some critical transcriptional factors, for example, $C / E B P a$ and PPAR $[80,81]$, lipid droplet accumulation, mitochondrial biogenesis [82], and a 20- to 30-fold increase in the concentration of numerous mitochondrial proteins [83]. ATP needed for the mitochondrial biogenesis, lipogenesis, and synthesis of numerous cytosolic and mitochondrial proteins is generated in the increased amounts due to the enhanced synthesis of mitochondrial DNA, subunits of respiratory complexes, cytochrome $c$, and enzymes of the tricarboxylic acid cycle [84]. In addition, tricarboxylic acid cycle generates citrate, which is then transported from the mitochondrion into the cytosol via the tricarboxylate carrier. Citrate is the only precursor of cytosolic acetylCoA, key intermediate used for fatty acid synthesis. Thus, citrate export from the mitochondria is essential during early differentiation stages of preadipocytes [85].

It has been also reported that a new adipose-specific protein, mouse ISG12b1, which is localized in the mitochondria, is predominantly overexpressed in adipocytes and dramatically induced at the terminal stage of adipogenesis. Functionally, ISG12b1 inhibits mitochondria biogenesis and adipocyte differentiation [86].

Taken together, although mitochondria in the brown fat are mainly acknowledged as important regulators of thermogenesis and those in the white fat as providers of constituents essential for lipogenesis, recent evidence suggests that mitochondria in adipose tissues might play plentiful roles in the regulation of the whole body energy homeostasis, crosstalk between adipose tissues and striated muscle, or control of insulin sensitivity and glucose metabolism [87-90] .

\section{Mitochondrial Dysfunction in Adipocyte}

Mitochondrial dysfunction can result from a decrease in mitochondrial biogenesis, reduced mitochondrial content, and/or a decrease in the protein content and activity of oxidative proteins "per unit of mitochondria" [91]. The major tissues affected by mitochondrial dysfunction are those with a high energy demand such as heart, muscles, brain, and endocrine glands [11, 92]. However, in the past few years, many studies have targeted mitochondria in adipocytes or adipose tissues providing convincing evidence that impairment of mitochondrial functions in adipocytes could have the whole body pathological consequences [12, 51]. As mitochondria house crucial metabolic processes like fatty acid oxidation, oxidative phosphorylation, and ROS production, it is not surprising that impaired mitochondrial activity often has an association with metabolism and adipocyte differentiation [92].

5.1. Mitochondrial Dysfunctions in Metabolic Disorders. As shown in previous paragraphs, mitochondria contribute substantially to normal functions of adipose tissues. Although it is not clear yet if the mitochondrial dysfunction plays a causative or adaptive role in various metabolic disorders, further research in the field could reveal the correct timing of processes leading to obesity, insulin resistance, diabetes mellitus, or lipodystrophy. Compelling lines of evidence indicate that major factors contributing to mitochondrial defects in adipose tissues are (i) oxidative stress, (ii) insulin resistance, (iii) genetic factors, and also (iv) sedentary lifestyle without physical activity [93].

Oxidative stress is defined as a disturbance in the balance between the production of ROS and antioxidant defence [94]. Mitochondria are a major source of cellular free radicals that might damage proteins, lipids, and DNA. Defects in the transfer of electrons across the mitochondrial membrane can cause electrons to accumulate on the respiratory chain complexes, which results in an increase of the potential 
for electrons to bind with free oxygen and stimulation of ROS production [95]. Furukawa et al. have shown that elevated levels of fatty acids increased oxidative stress via NADPH oxidase activation in cultured adipocytes. ROS then caused dysregulated production of various adipocytokines, including adiponectin, plasminogen activator inhibitor-1, IL6 , and monocyte chemotactic protein 1 [96]. In obese mice, fat accumulation correlated with systemic oxidative stress and treatment with NADPH oxidase inhibitor reduced ROS production in adipose tissue, attenuated the dysregulation of adipocytokines, and improved diabetes, hyperlipidaemia, and hepatic steatosis in humans and mice [96]. Wang et al. have reported that higher intracellular ROS levels elicited by mitochondrial dysfunction resulted in the impairment of adipocyte function in the maintenance of glucose homeostasis through attenuation of insulin signalling, downregulation of the glucose transporter (GLUT4) expression, and decrease in adiponectin secretion [97].

Insulin resistance is a key defect associated with obesity and type 2 diabetes. It is defined as "a relative impairment in the ability of insulin to exert its effects on glucose, protein, and lipid metabolism in target tissues" [98]. Decreased insulin response to glucose, dyslipidaemia, and obesity frequently progress into overt type 2 diabetes with a decline in $\beta$-cell function, sustained hyperglycaemia, and increased advanced glycation end products (AGE) formation. In turn, AGE accumulation in adipose tissue may contribute to obesity-associated insulin resistance [99]. The role of mitochondria in adipose tissues in the onset and progression of insulin resistance is still a matter of controversy. Some recent findings suggest that dysregulation of mitochondrial calcium influx and efflux could be a crucial factor contributing to decreased insulin sensitivity [100] that is associated with impaired mitochondrial biogenesis and decreased expression of mitochondrial proteins in adipose tissues [101, 102]. However, mitochondrial dysfunction is not always essential for insulin resistance as reported by Martin et al. [103]. In addition, ROS-induced mitochondrial dysfunction seems to be a valid mechanism leading to insulin resistance in skeletal muscle, but not necessarily in adipocytes [103].

Genetic factors could play an important role in the onset and progression of obesity or type 2 diabetes mellitus. Among genes with positive associations of variants with obesity or obesity-related phenotypes, there are some deeply involved in the regulation of mitochondrial activity and biogenesis in adipose tissues, like ADRB3 (adrenergic, $\beta 3$ receptor), INS (insulin), PLIN (perilipin), PPAR $\gamma$ (peroxisome proliferative activated receptor, gamma), or UCP1-UCP13 (uncoupling proteins 1-3) [104]. In addition, impaired expression of genes related to mitochondrial functions in adipose tissues can be caused by acquired mutations of both mitochondrial and nuclear genomes. Mitochondrial DNA displays a high mutation rate due to its specific features, like limited repair, proximity to ROS production, and absence of histones [105]. Defects in the expression of mitochondria-related genes were found at the mRNA as well as the protein levels in various organs and tissues including adipose cells [106-110].

Transcriptional coactivators PGC- $1 \alpha$ and PGC- $1 \beta$ seem to be of particular importance in coordination of expression of mitochondrial and nuclear genes related to mitochondrial functions in both BAT and WAT [111, 112]. PGC- $1 \alpha$ is able to direct human WAT PPAR $\gamma$ toward a transcriptional program linked to energy dissipation through an increased expression of UCP1 [113]. Accordingly, decreased PGC-1 $\alpha$ mRNA levels were reported in subcutaneous fat in morbidly obese subjects. Although it is not clear whether low PGC-1 $\alpha$ expression is a prelude to the development of obesity or a consequence of it, upregulation of expression of thermogenic genes in white adipose tissue could offer new tool in the therapy of obesity [114].

However, it should be noted that impairment of expression of mitochondria-related genes does not necessarily lead to obesity as documented by manipulations with mitochondrial transcription factor A (TFAM), one of the major controllers of mitochondrial mass: in mice deficient in TFAM in adipocytes, activity of proteins in respiratory complexes I, III, and IV was severely compromised, which resulted in adipocyte death and inflammation in WAT and whitening of BAT [88].

Changes in human behaviour and lifestyle over the last century have resulted in a dramatic increase in the incidence of diabetes and obesity worldwide. Sedentary lifestyle, changes in work (from heavy labour to sedentary) have had an impact on human health $[4,115]$. Physical activity is a major regulator of mitochondrial function in muscle cells and long-time inactivity is associated with reduced mitochondrial function and number [116].

In adipose tissues, regular physical activity and exercise training have long been known to cause increased expression and activity of mitochondrial proteins $[117,118]$. In the last decade, the "beiging" of WAT associated with the expression of typical markers of BAT (like UCP1) in white adipocytes was revealed in response to exercise training $[119,120]$. In rodents, even a single bout of exercise increased expression of a marker for mitochondrial biogenesis, PGC- $1 \alpha$ mRNA in WAT [121]. This increase was presumably induced by stimulation $\beta$-adrenergic receptors at least in visceral WAT [122]. In the subcutaneous WAT, endothelial nitric oxide synthase has been proposed to regulate training-induced increases in mitochondrial biogenesis [118].

\subsection{Mitochondrial Dysfunction during Adipocyte Differen-} tiation. There is ample evidence that any damage to the mitochondrial respiratory chain results in compromised adipocyte differentiation. Inhibition of complex I by rotenone led to the significant reduction in the expression of mitochondrial malate dehydrogenase and a number of differentiation transcription factors, like PGC- $1 \beta$, PPAR $\gamma$, CAAT/enhancer binding protein alpha $(\mathrm{C} / \mathrm{EBP} \alpha)$, and sterol regulatory element binding protein-1c (SREBP-1c). In addition, apparent decreases in the synthesis of triglycerides and ATP were reported [84]. Antimycin A, inhibitor of complex III, and oligomycin, inhibitor of ATP synthase commonly used for developing of mitochondrial dysfunction models, also prevented preadipocyte differentiation $[123,124]$.

High concentrations of mitochondrial ROS generated by the respiratory chain have also detrimental influence on 
adipoblast proliferation and differentiation. Genetic manipulation of mitochondrial complex III revealed that ROS generated by this complex were required to initiate primary human mesenchymal stem cells differentiation [81]. Thus, the production of ROS and mitochondrial metabolism are not simply a consequence of adipogenesis but are causal factors in promoting adipocyte differentiation [81].

\section{Conclusions}

Adipose tissue is an extremely plastic organ capable of massive expansion, reduction, or transformation according to appropriate stimulation. Research motivated mainly by the desire to understand adipocytes in the context of obesity and related diseases resulted not only in promising data opening new ways to fight obesity, but also in the discovery of multipotent stem cells within WAT [125]. It is now widely accepted that adipose tissue acts not only as repository for excess nutrients but also as integrator and regulator of the balance between food intake and energy output. It secretes a number of substances affecting the function of several organs in the body and also the function of adipose tissue itself [51, 126, 127]. This review summarizes the main characteristics of each adipose tissue subtype and describes morphological and functional modifications focusing on mitochondria and their activity in healthy and unhealthy adipocytes. Increasing evidence in adipocyte-related mitochondrial research demonstrates the important role of mitochondria in the onset or progression of obesity and related pathologies and offers a large spectrum of potential therapeutic targets, like differentiation and transformation of adipocytes, ROS production, substrate channelling to energy dissipation, or changes in the lifestyle.

\section{Conflict of Interests}

The authors declare that they have no competing interests.

\section{Authors' Contribution}

Miroslava Cedikova and Michaela Kripnerová contributed equally to this work.

\section{Acknowledgments}

This study was supported by the National Sustainability Program I (NPU I) no. LO1503 provided by the Ministry of Education Youth and Sports of the Czech Republic, the Charles University Research Fund (no. P36), the Specific Student Research Project nos. 260281/2016 and 260283/2016 of the Charles University in Prague, and the Project NT 143303/2013.

\section{References}

[1] A. V. B. Castro, C. M. Kolka, S. P. Kim, and R. N. Bergman, "Obesity, insulin resistance and comorbidities-mechanisms of association," Arquivos Brasileiros de Endocrinologia e Metabologia, vol. 58, no. 6, pp. 600-609, 2014.

[2] M. Luna-Luna, A. Medina-Urrutia, G. Vargas-Alarcón, F. Coss-Rovirosa, J. Vargas-Barrón, and Ó. Pérez-Méndez, "Adipose tissue in metabolic syndrome: onset and progression of atherosclerosis," Archives of Medical Research, vol. 46, no. 5, pp. 392-407, 2015.

[3] J. F. Mission, N. E. Marshall, and A. B. Caughey, "Pregnancy risks associated with obesity," Obstetrics and Gynecology Clinics of North America, vol. 42, no. 2, pp. 335-353, 2015.

[4] P. Zimmet, K. G. M. M. Alberti, and J. Shaw, "Global and societal implications of the diabetes epidemic," Nature, vol. 414, no. 6865, pp. 782-787, 2001.

[5] L. Cai, J. Lubitz, K. M. Flegal, and E. R. Pamuk, “The predicted effects of chronic obesity in middle age on medicare costs and mortality," Medical Care, vol. 48, no. 6, pp. 510-517, 2010.

[6] A. Géloën, P. E. Roy, and L. J. Bukowiecki, "Regression of white adipose tissue in diabetic rats," American Journal of PhysiologyEndocrinology and Metabolism, vol. 257, no. 4, part 1, pp. E547E553, 1989.

[7] B. B. Lowell and J. S. Flier, "Brown adipose tissue, $\beta 3$-adrenergic receptors, and obesity," Annual Review of Medicine, vol. 48, pp. 307-316, 1997.

[8] A. Park, W. K. Kim, and K.-H. Bae, "Distinction of white, beige and brown adipocytes derived from mesenchymal stem cells," World Journal of Stem Cells, vol. 6, no. 1, pp. 33-42, 2014.

[9] M. Giralt and F. Villarroya, "White, brown, beige/brite: different adipose cells for different functions?" Endocrinology, vol. 154, no. 9, pp. 2992-3000, 2013.

[10] A. Cook and C. Cowan, "Adipose," in StemBook, Harvard Stem Cell Institute, Cambridge, Mass, USA, 2008.

[11] A. De Pauw, S. Tejerina, M. Raes, J. Keijer, and T. Arnould, "Mitochondrial (dys)function in adipocyte (de)differentiation and systemic metabolic alterations," The American Journal of Pathology, vol. 175, no. 3, pp. 927-939, 2009.

[12] X. Yin, I. R. Lanza, J. M. Swain, M. G. Sarr, K. S. Nair, and M. D. Jensen, "Adipocyte mitochondrial function is reduced in human obesity independent of fat cell size," Journal of Clinical Endocrinology and Metabolism, vol. 99, no. 2, pp. E209-E216, 2014.

[13] A. Peschechera and J. Eckel, "Browning' of adipose tissueregulation and therapeutic perspectives," Archives of Physiology and Biochemistry, vol. 119, no. 4, pp. 151-160, 2013.

[14] C.-H. Wang, C.-C. Wang, and Y.-H. Wei, "Mitochondrial dysfunction in insulin insensitivity: implication of mitochondrial role in type 2 diabetes," Annals of the New York Academy of Sciences, vol. 1201, pp. 157-165, 2010.

[15] D. C. Logan, “The mitochondrial compartment," Journal of Experimental Botany, vol. 57, no. 6, pp. 1225-1243, 2006.

[16] Y. Zhang, X. Zeng, and S. Jin, "Autophagy in adipose tissue biology," Pharmacological Research, vol. 66, no. 6, pp. 505-512, 2012.

[17] J.-A. Kim, Y. Wei, and J. R. Sowers, "Role of mitochondrial dysfunction in insulin resistance," Circulation Research, vol. 102, no. 4, pp. 401-414, 2008.

[18] G. Benard, B. Faustin, E. Passerieux et al., "Physiological diversity of mitochondrial oxidative phosphorylation," American Journal of Physiology-Cell Physiology, vol. 291, no. 6, pp. C1172C1182, 2006.

[19] M. Zeviani and S. Di Donato, "Mitochondrial disorders," Brain, vol. 127, no. 10, pp. 2153-2172, 2004. 
[20] G. Lenaz, "Role of mitochondria in oxidative stress and ageing," Biochimica et Biophysica Acta-Bioenergetics, vol. 1366, no. 1-2, pp. 53-67, 1998.

[21] X. Wang, "The expanding role of mitochondria in apoptosis," Genes and Development, vol. 15, no. 22, pp. 2922-2933, 2001.

[22] G. Medina-Gómez, "Mitochondria and endocrine function of adipose tissue," Best Practice and Research: Clinical Endocrinology and Metabolism, vol. 26, no. 6, pp. 791-804, 2012.

[23] V. Peirce, S. Carobbio, and A. Vidal-Puig, "The different shades of fat," Nature, vol. 510, no. 7503, pp. 76-83, 2014.

[24] J. M. Stephens, "The fat controller: adipocyte development," PLoS Biology, vol. 10, no. 11, Article ID e1001436, 2012.

[25] T. Shan, X. Liang, P. Bi, P. Zhang, W. Liu, and S. Kuang, "Distinct populations of adipogenic and myogenic Myf5-lineage progenitors in white adipose tissues," Journal of Lipid Research, vol. 54, no. 8, pp. 2214-2224, 2013.

[26] J. Sanchez-Gurmaches, C.-M. Hung, C. A. Sparks, Y. Tang, H. Li, and D. A. Guertin, "PTEN loss in the Myf5 lineage redistributes body fat and reveals subsets of white adipocytes that arise from Myf5 precursors," Cell Metabolism, vol. 16, no. 3, pp. 348-362, 2012.

[27] A. M. Cypess, A. P. White, C. Vernochet et al., "Anatomical localization, gene expression profiling and functional characterization of adult human neck brown fat," Nature Medicine, vol. 19, no. 5, pp. 635-639, 2013.

[28] D. Vargas, W. Rosales, and F. Lizcano, "Modifications of human subcutaneous admsc after PPAR $\gamma$ activation and cold exposition," Stem Cells International, vol. 2015, Article ID 196348, 8 pages, 2015.

[29] M. E. Symonds, "Brown adipose tissue growth and development," Scientifica, vol. 2013, Article ID 305763, 14 pages, 2013.

[30] N. Z. Jespersen, T. J. Larsen, L. Peijs et al., "A classical brown adipose tissue mrna signature partly overlaps with brite in the supraclavicular region of adult humans," Cell Metabolism, vol. 17, no. 5, pp. 798-805, 2013.

[31] L. Z. Sharp, K. Shinoda, H. Ohno et al., "Human BAT possesses molecular signatures that resemble beige/brite cells," PLOS ONE, vol. 7, no. 11, Article ID e49452, 2012.

[32] S. Corvera and O. Gealekman, "Adipose tissue angiogenesis: impact on obesity and type-2 diabetes," Biochimica et Biophysica Acta-Molecular Basis of Disease, vol. 1842, no. 3, pp. 463-472, 2014.

[33] A. Y. Lemoine, S. Ledoux, and E. Larger, "Adipose tissue angiogenesis in obesity," Thrombosis and Haemostasis, vol. 110, no. 4, pp. 661-669, 2013.

[34] K. Sarjeant and J. M. Stephens, “Adipogenesis," Cold Spring Harbor perspectives in Biology, vol. 4, no. 9, Article ID a008417, 2012.

[35] J. Orava, P. Nuutila, T. Noponen et al., "Blunted metabolic responses to cold and insulin stimulation in brown adipose tissue of obese humans," Obesity, vol. 21, no. 11, pp. 2279-2287, 2013.

[36] N. Tewari, S. Awad, I. A. Macdonald, and D. N. Lobo, "Obesityrelated insulin resistance: implications for the surgical patient," International Journal of Obesity, vol. 39, no. 11, pp. 1575-1588, 2015.

[37] A.-L. Poher, J. Altirriba, C. Veyrat-Durebex, and F. RohnerJeanrenaud, "Brown adipose tissue activity as a target for the treatment of obesity/insulin resistance," Frontiers in Physiology, vol. 6, article 4, 2015.
[38] K. Schlessinger, W. Li, Y. Tan et al., "Gene expression in WAT from healthy humans and monkeys correlates with FGF21induced browning of WAT in mice," Obesity, vol. 23, no. 9, pp. 1818-1829, 2015.

[39] K. A. Virtanen, M. E. Lidell, J. Orava et al., "Functional brown adipose tissue in healthy adults," The New England Journal of Medicine, vol. 360, no. 15, pp. 1518-1525, 2009.

[40] A. M. Cypess, S. Lehman, G. Williams et al., "Identification and importance of brown adipose tissue in adult humans," The New England Journal of Medicine, vol. 360, no. 15, pp. 1509-1517, 2009.

[41] M. Stephens, M. Ludgate, and D. A. Rees, "Brown fat and obesity: the next big thing?" Clinical Endocrinology, vol. 74, no. 6, pp. 661-670, 2011.

[42] J. Wu, P. Boström, L. M. Sparks et al., "Beige adipocytes are a distinct type of thermogenic fat cell in mouse and human," Cell, vol. 150, no. 2, pp. 366-376, 2012.

[43] T. B. Waldén, I. R. Hansen, J. A. Timmons, B. Cannon, and J. Nedergaard, "Recruited vs. nonrecruited molecular signatures of brown, 'brite,' and white adipose tissues," American Journal of Physiology_Endocrinology and Metabolism, vol. 302, no. 1, pp. E19-E31, 2012.

[44] J. Himms-Hagen, A. Melnyk, M. C. Zingaretti, E. Ceresi, G. Barbatelli, and S. Cinti, "Multilocular fat cells in WAT of CL-316243-treated rats derive directly from white adipocytes," American Journal of Physiology-Cell Physiology, vol. 279, no. 3, pp. C670-C681, 2000.

[45] M. Morroni, A. Giordano, M. C. Zingaretti et al., "Reversible transdifferentiation of secretory epithelial cells into adipocytes in the mammary gland," Proceedings of the National Academy of Sciences of the United States of America, vol. 101, no. 48, pp. 16801-16806, 2004.

[46] Q. A. Wang, C. Tao, R. K. Gupta, and P. E. Scherer, "Tracking adipogenesis during white adipose tissue development, expansion and regeneration," Nature Medicine, vol. 19, no. 10, pp.1338$1344,2013$.

[47] R. De Matteis, F. Lucertini, M. Guescini et al., "Exercise as a new physiological stimulus for brown adipose tissue activity," Nutrition, Metabolism and Cardiovascular Diseases, vol. 23, no. 6, pp. 582-590, 2013.

[48] C. Sun, R. Zeng, G. Cao, Z. Song, Y. Zhang, and C. Liu, "Vibration training triggers brown adipocyte relative protein expression in rat white adipose tissue," BioMed Research International, vol. 2015, Article ID 919401, 10 pages, 2015.

[49] A. Bartelt and J. Heeren, "Adipose tissue browning and metabolic health," Nature Reviews Endocrinology, vol. 10, no. 1, pp. 24-36, 2014.

[50] F. Forner, C. Kumar, C. A. Luber, T. Fromme, M. Klingenspor, and M. Mann, "Proteome differences between brown and white fat mitochondria reveal specialized metabolic functions," Cell Metabolism, vol. 10, no. 4, pp. 324-335, 2009.

[51] S. Boudina and T. E. Graham, "Mitochondrial function/dysfunction in white adipose tissue," Experimental Physiology, vol. 99, no. 9, pp. 1168-1178, 2014.

[52] C. M. Oller do Nascimento, E. B. Ribeiro, and L. M. Oyama, "Metabolism and secretory function of white adipose tissue: effect of dietary fat," Anais da Academia Brasileira de Ciências, vol. 81, no. 3, pp. 453-466, 2009.

[53] J. Orava, P. Nuutila, M. E. Lidell et al., "Different metabolic responses of human brown adipose tissue to activation by cold and insulin," Cell Metabolism, vol. 14, no. 2, pp. 272-279, 2011. 
[54] M. C. Sugden and M. J. Holness, "Mechanisms underlying regulation of the expression and activities of the mammalian pyruvate dehydrogenase kinases," Archives of Physiology and Biochemistry, vol. 112, no. 3, pp. 139-149, 2006.

[55] D. G. Nicholls and R. M. Locke, "Thermogenic mechanisms in brown fat," Physiological Reviews, vol. 64, no. 1, pp. 1-64, 1984.

[56] B. Cannon and J. Nedergaard, "Brown adipose tissue: function and physiological significance," Physiological Reviews, vol. 84, no. 1, pp. 277-359, 2004.

[57] S. Kajimura and M. Saito, "A new era in brown adipose tissue biology: molecular control of brown fat development and energy homeostasis," Annual Review of Physiology, vol. 76, pp. 225-249, 2014.

[58] R. A. Busiello, S. Savarese, and A. Lombardi, "Mitochondrial uncoupling proteins and energy metabolism," Frontiers in Physiology, vol. 6, article 36, 2015.

[59] D. G. Nicholls, "Stoicheiometries of proton translocation by mitochondria," Biochemical Society Transactions, vol. 5, no. 1, pp. 200-203, 1977.

[60] F. Bouillaud, E. Couplan, C. Pecqueur, and D. Ricquier, "Homologues of the uncoupling protein from brown adipose tissue (UCP1): UCP2, UCP3, BMCP1 and UCP4," Biochimica et Biophysica Acta (BBA)_Bioenergetics, vol. 1504, no. 1, pp. 107119, 2001.

[61] M. Nibbelink, K. Moulin, E. Arnaud, C. Duval, L. Pénicaud, and L. Casteilla, "Brown fat UCP1 is specifically expressed in uterine longitudinal smooth muscle cells," The Journal of Biological Chemistry, vol. 276, no. 50, pp. 47291-47295, 2001.

[62] M. Kim, T. Goto, R. Yu et al., "Fish oil intake induces UCP1 upregulation in brown and white adipose tissue via the sympathetic nervous system," Scientific Reports, vol. 5, Article ID 18013, 2015.

[63] J. Nedergaard and B. Cannon, “The 'novel' 'uncoupling' UCP2 and UCP3: what do they really do? Pros and cons for suggested functions," Experimental Physiology, vol. 88, no. 1, pp. 65-84, 2003.

[64] K. S. Echtay, "Mitochondrial uncoupling proteins-what is their physiological role?" Free Radical Biology and Medicine, vol. 43, no. 10, pp. 1351-1371, 2007.

[65] F. E. Sluse, W. Jarmuszkiewicz, R. Navet, P. Douette, G. Mathy, and C. M. Sluse-Goffart, "Mitochondrial UCPs: new insights into regulation and impact," Biochimica et Biophysica Acta (BBA)-Bioenergetics, vol. 1757, no. 5-6, pp. 480-485, 2006.

[66] G. Mattiasson and P. G. Sullivan, "The emerging functions of UCP2 in health, disease, and therapeutics," Antioxidants and Redox Signaling, vol. 8, no. 1-2, pp. 1-38, 2006.

[67] C. Pecqueur, M.-C. Alves-Guerra, C. Gelly et al., "Uncoupling protein 2, in vivo distribution, induction upon oxidative stress, and evidence for translational regulation," The Journal of Biological Chemistry, vol. 276, no. 12, pp. 8705-8712, 2001.

[68] G. G. Power, "Biology of temperature: the mammalian fetus," Journal of Developmental Physiology, vol. 12, no. 6, pp. 295-304, 1989.

[69] B. B. Lowell and B. M. Spiegelman, "Towards a molecular understanding of adaptive thermogenesis," Nature, vol. 404, no. 6778, pp. 652-660, 2000.

[70] M. Zhang, M. Wang, and Z.-T. Zhao, "Uncoupling protein 2 gene polymorphisms in association with overweight and obesity susceptibility: a meta-analysis," Meta Gene, vol. 2, no. 1, pp. 143-159, 2014.
[71] A. Acosta, M. Camilleri, A. Shin et al., "Association of UCP3 rs1626521 with obesity and stomach functions in humans," Obesity, vol. 23, no. 4, pp. 898-906, 2015.

[72] A. L. Carey, C. Vorlander, M. Reddy-Luthmoodoo et al., "Reduced UCP-1 content in in vitro differentiated beige/brite adipocytes derived from preadipocytes of human subcutaneous white adipose tissues in obesity," PLoS ONE, vol. 9, no. 3, Article ID e91997, 2014.

[73] A. T. Akhmedov, V. Rybin, and J. Marín-García, "Mitochondrial oxidative metabolism and uncoupling proteins in the failing heart," Heart Failure Reviews, vol. 20, no. 2, pp. 227-249, 2015.

[74] C. Cornelius, A. Trovato Salinaro, M. Scuto et al., "Cellular stress response, sirtuins and UCP proteins in Alzheimer disease: role of vitagenes," Immunity and Ageing, vol. 10, no. 1, article 41, 2013.

[75] D. Robbins and Y. Zhao, "New aspects of mitochondrial Uncoupling Proteins (UCPs) and their roles in tumorigenesis," International Journal of Molecular Sciences, vol. 12, no. 8, pp. 5285-5293, 2011.

[76] L. Wilson-Fritch, S. Nicoloro, M. Chouinard et al., "Mitochondrial remodeling in adipose tissue associated with obesity and treatment with rosiglitazone," The Journal of Clinical Investigation, vol. 114, no. 9, pp. 1281-1289, 2004.

[77] E. Yehuda-Shnaidman, B. Buehrer, J. Pi, N. Kumar, and S. Collins, "Acute stimulation of white adipocyte respiration by PKA-induced lipolysis," Diabetes, vol. 59, no. 10, pp. 2474-2483, 2010.

[78] Z. López-Ibarra, J. Modrego, M. Valero-Muñoz et al., "Metabolic differences between white and brown fat from fasting rabbits at physiological temperature," Journal of Molecular Endocrinology, vol. 54, no. 2, pp. 105-113, 2015.

[79] J. Kopecký, M. Rossmeisl, P. Flachs, K. Bardová, and P. Brauner, "Mitochondrial uncoupling and lipid metabolism in adipocytes," Biochemical Society Transactions, vol. 29, part 6, pp. 791-797, 2001.

[80] F. M. Gregoire, C. M. Smas, and H. S. Sul, "Understanding adipocyte differentiation," Physiological Reviews, vol. 78, no. 3, pp. 783-809, 1998.

[81] K. V. Tormos, E. Anso, R. B. Hamanaka et al., "Mitochondrial complex III ROS regulate adipocyte differentiation," Cell Metabolism, vol. 14, no. 4, pp. 537-544, 2011.

[82] D. Liu, Y. Lin, T. Kang et al., "Mitochondrial dysfunction and adipogenic reduction by prohibitin silencing in 3T3-L1 cells," PLoS ONE, vol. 7, no. 3, Article ID e34315, 2012.

[83] L. Wilson-Fritch, A. Burkart, G. Bell et al., "Mitochondrial biogenesis and remodeling during adipogenesis and in response to the insulin sensitizer rosiglitazone," Molecular and Cellular Biology, vol. 23, no. 3, pp. 1085-1094, 2003.

[84] R.-H. Lu, H. Ji, Z.-G. Chang, S.-S. Su, and G.-S. Yang, "Mitochondrial development and the influence of its dysfunction during rat adipocyte differentiation," Molecular Biology Reports, vol. 37, no. 5, pp. 2173-2182, 2010.

[85] K. Kajimoto, H. Terada, Y. Baba, and Y. Shinohara, "Essential role of citrate export from mitochondria at early differentiation stage of 3T3-L1 cells for their effective differentiation into fat cells, as revealed by studies using specific inhibitors of mitochondrial di- and tricarboxylate carriers," Molecular Genetics and Metabolism, vol. 85, no. 1, pp. 46-53, 2005.

[86] B. Li, J. Shin, and K. Lee, "Interferon-stimulated gene ISG12b1 inhibits adipogenic differentiation and mitochondrial biogenesis in 3T3-L1 cells," Endocrinology, vol. 150, no. 3, pp. 1217-1224, 2009. 
[87] Y. R. Yang, H.-J. Jang, S.-S. Choi et al., "Obesity resistance and increased energy expenditure by white adipose tissue browning in $\mathrm{gga}^{+/-}$mice," Diabetologia, vol. 58, no. 12, pp. 2867-2876, 2015.

[88] C. Vernochet, F. Damilano, A. Mourier et al., "Adipose tissue mitochondrial dysfunction triggers a lipodystrophic syndrome with insulin resistance, hepatosteatosis, and cardiovascular complications," The FASEB Journal, vol. 28, no. 10, pp. 44084419, 2014.

[89] M. Keuper, M. Jastroch, C.-X. Yi et al., "Spare mitochondrial respiratory capacity permits human adipocytes to maintain ATP homeostasis under hypoglycemic conditions," The FASEB Journal, vol. 28, no. 2, pp. 761-770, 2014.

[90] J. Dong, Y. Dong, Y. Dong, F. Chen, W. E. Mitch, and L. Zhang, "Inhibition of myostatin in mice improves insulin sensitivity via irisin-mediated cross talk between muscle and adipose tissues," International Journal of Obesity, vol. 40, no. 3, pp. 434-442, 2016.

[91] M. K. Montgomery and N. Turner, "Mitochondrial dysfunction and insulin resistance: an update," Endocrine Connections, vol. 4, no. 1, pp. R1-R15, 2014.

[92] D. C. Chan, "Mitochondria: dynamic organelles in disease, aging, and development," Cell, vol. 125, no. 7, pp. 1241-1252, 2006.

[93] N. Turner and L. K. Heilbronn, "Is mitochondrial dysfunction a cause of insulin resistance?" Trends in Endocrinology and Metabolism, vol. 19, no. 9, pp. 324-330, 2008.

[94] D. J. Betteridge, "What is oxidative stress?" Metabolism: Clinical and Experimental, vol. 49, no. 2, supplement 1, pp. 3-8, 2000.

[95] D. L. Johannsen and E. Ravussin, "The role of mitochondria in health and disease," Current Opinion in Pharmacology, vol. 9, no. 6, pp. 780-786, 2009.

[96] S. Furukawa, T. Fujita, M. Shimabukuro et al., "Increased oxidative stress in obesity and its impact on metabolic syndrome," The Journal of Clinical Investigation, vol. 114, no. 12, pp. 1752-1761, 2004.

[97] C.-H. Wang, C.-C. Wang, H.-C. Huang, and Y.-H. Wei, "Mitochondrial dysfunction leads to impairment of insulin sensitivity and adiponectin secretion in adipocytes," The FEBS Journal, vol. 280, no. 4, pp. 1039-1050, 2013.

[98] C. R. Kahn, "Insulin resistance, insulin insensitivity, and insulin unresponsiveness: a necessary distinction," Metabolism: Clinical and Experimental, vol. 27, no. 12, supplement 2, pp. 1893-1902, 1978.

[99] F. Boyer, J. B. Vidot, A. G. Dubourg, P. Rondeau, M. F. Essop, and E. Bourdon, "Oxidative stress and adipocyte biology: focus on the role of AGEs," Oxidative Medicine and Cellular Longevity, vol. 2015, Article ID 534873, 9 pages, 2015.

[100] C.-H. Wang, T.-F. Tsai, and Y.-H. Wei, "Role of mitochondrial dysfunction and dysregulation of $\mathrm{Ca}^{2+}$ homeostasis in insulin insensitivity of mammalian cells," Annals of the New York Academy of Sciences, vol. 1350, pp. 66-76, 2015.

[101] S. Heinonen, J. Buzkova, M. Muniandy et al., "Impaired mitochondrial biogenesis in adipose tissue in acquired obesity," Diabetes, vol. 64, no. 9, pp. 3135-3145, 2015.

[102] L. N. Sutherland, L. C. Capozzi, N. J. Turchinsky, R. C. Bell, and D. C. Wright, "Time course of high-fat diet-induced reductions in adipose tissue mitochondrial proteins: potential mechanisms and the relationship to glucose intolerance," American Journal of Physiology-Endocrinology and Metabolism, vol. 295, no. 5, pp. E1076-E1083, 2008.
[103] S. D. Martin, S. Morrison, N. Konstantopoulos, and S. L. McGee, "Mitochondrial dysfunction has divergent, cell type-dependent effects on insulin action," Molecular Metabolism, vol. 3, no. 4, pp. 408-418, 2014.

[104] A. J. Walley, A. I. F. Blakemore, and P. Froguel, "Genetics of obesity and the prediction of risk for health," Human Molecular Genetics, vol. 15, no. 2, pp. R124-R130, 2006.

[105] G. C. Kujoth, P. C. Bradshaw, S. Haroon, and T. A. Prolla, "The role of mitochondrial DNA mutations in mammalian aging," PLoS Genetics, vol. 3, article e24, 2007.

[106] J. M. Kristensen, V. Skov, S. J. Petersson et al., "A PGC-1 $\alpha$ - and muscle fibre type-related decrease in markers of mitochondrial oxidative metabolism in skeletal muscle of humans with inherited insulin resistance," Diabetologia, vol. 57, no. 5, pp. 10061015, 2014.

[107] V. Skov, D. Glintborg, S. Knudsen et al., "Reduced expression of nuclear-encoded genes involved in mitochondrial oxidative metabolism in skeletal muscle of insulin-resistant women with polycystic ovary syndrome," Diabetes, vol. 56, no. 9, pp. 23492355, 2007.

[108] C.-L. Gao, C. Zhu, Y.-P. Zhao et al., "Mitochondrial dysfunction is induced by high levels of glucose and free fatty acids in 3T3L1 adipocytes," Molecular and Cellular Endocrinology, vol. 320, no. 1-2, pp. 25-33, 2010.

[109] M. A. Kamel, M. H. Helmy, M. Y. Hanafi, S. A. Mahmoud, and $\mathrm{H}$. Abo Elfetooh, "Impaired peripheral glucose sensing in F1 offspring of diabetic pregnancy," Journal of Physiology and Biochemistry, vol. 70, no. 3, pp. 685-699, 2014.

[110] M. Wang, X. C. Wang, Z. Y. Zhang, B. Mou, and R. M. $\mathrm{Hu}$, "Impaired mitochondrial oxidative phosphorylation in multiple insulin-sensitive tissues of humans with type 2 diabetes mellitus," Journal of International Medical Research, vol. 38, no. 3, pp. 769-781, 2010.

[111] P. Puigserver, Z. Wu, C. W. Park, R. Graves, M. Wright, and B. M. Spiegelman, "A cold-inducible coactivator of nuclear receptors linked to adaptive thermogenesis," Cell, vol. 92, no. 6, pp. 829839, 1998.

[112] R. Pardo, N. Enguix, J. Lasheras, J. E. Feliu, A. Kralli, and J. A. Villena, "Rosiglitazone-induced mitochondrial biogenesis in white adipose tissue is independent of peroxisome proliferatoractivated receptor $\gamma$ coactivator- $1 \alpha$, PLoS ONE, vol. 6, no. 11, Article ID e26989, 2011.

[113] C. Tiraby, G. Tavernier, C. Lefort et al., "Acquirement of brown fat cell features by human white adipocytes," The Journal of Biological Chemistry, vol. 278, no. 35, pp. 33370-33376, 2003.

[114] R. K. Semple, V. C. Crowley, C. P. Sewter et al., "Expression of the thermogenic nuclear hormone receptor coactivator PGClalpha is reduced in the adipose tissue of morbidly obese subjects," International Journal of Obesity, vol. 28, no. 1, pp. 176179, 2004.

[115] P. Zimmet, "Globalization, coca-colonization and the chronic disease epidemic: can the doomsday scenario be averted?" Journal of Internal Medicine, vol. 247, no. 3, pp. 301-310, 2000.

[116] H. Hoppeler and M. Flück, "Plasticity of skeletal muscle mitochondria: structure and function," Medicine and Science in Sports and Exercise, vol. 35, no. 1, pp. 95-104, 2003.

[117] B. Stallknecht, J. Vinten, T. Ploug, and H. Galbo, "Increased activities of mitochondrial enzymes in white adipose tissue in trained rats," American Journal of Physiology-Endocrinology and Metabolism, vol. 261, no. 3, part 1, pp. E410-E414, 1991. 
[118] E. Trevellin, M. Scorzeto, M. Olivieri et al., "Exercise training induces mitochondrial biogenesis and glucose uptake in subcutaneous adipose tissue through eNOS-dependent mechanisms," Diabetes, vol. 63, no. 8, pp. 2800-2811, 2014.

[119] J. G. Knudsen, M. Murholm, A. L. Carey et al., "Role of IL6 in exercise training- and cold-induced UCP1 expression in subcutaneous white adipose tissue," PLoS ONE, vol. 9, no. 1, Article ID e84910, 2014.

[120] S. Ringholm, J. Grunnet Knudsen, L. Leick, A. Lundgaard, M. Munk Nielsen, and H. Pilegaard, "PGC-1 $\alpha$ is required for exercise- and exercise training-induced UCP1 up-regulation in mouse white adipose tissue," PLoS ONE, vol. 8, no. 5, Article ID e64123, 2013.

[121] L. N. Sutherland, M. R. Bomhof, L. C. Capozzi, S. A. U. Basaraba, and D. C. Wright, "Exercise and adrenaline increase PGC-1 $\alpha$ mRNA expression in rat adipose tissue," The Journal of Physiology, vol. 587, no. 7, pp. 1607-1617, 2009.

[122] K. I. Stanford, R. J. Middelbeek, K. L. Townsend et al., "A novel role for subcutaneous adipose tissue in exercise-induced improvements in glucose homeostasis," Diabetes, vol. 64, no. 6, pp. 2002-2014, 2015.

[123] A. Carrière, M.-C. Carmona, Y. Fernandez et al., "Mitochondrial reactive oxygen species control the transcription factor CHOP-10/GADD153 and adipocyte differentiation: a mechanism for hypoxia-dependent effect," The Journal of Biological Chemistry, vol. 279, no. 39, pp. 40462-40469, 2004.

[124] Y. Zhang, G. Marsboom, P. T. Toth, and J. Rehman, "Mitochondrial respiration regulates adipogenic differentiation of human mesenchymal stem cells," PLoS ONE, vol. 8, no. 10, Article ID e77077, 2013.

[125] W. P. Cawthorn, E. L. Scheller, and O. A. MacDougald, "Adipose tissue stem cells meet preadipocyte commitment: going back to the future," Journal of Lipid Research, vol. 53, no. 2, pp. 227-246, 2012.

[126] M. A. Exley, L. Hand, D. O’Shea, and L. Lynch, "Interplay between the immune system and adipose tissue in obesity," Journal of Endocrinology, vol. 223, no. 2, pp. R41-R48, 2014.

[127] C. H. Saely, K. Geiger, and H. Drexel, "Brown versus white adipose tissue: a mini-review," Gerontology, vol. 58, no. 1, pp. 15-23, 2012. 

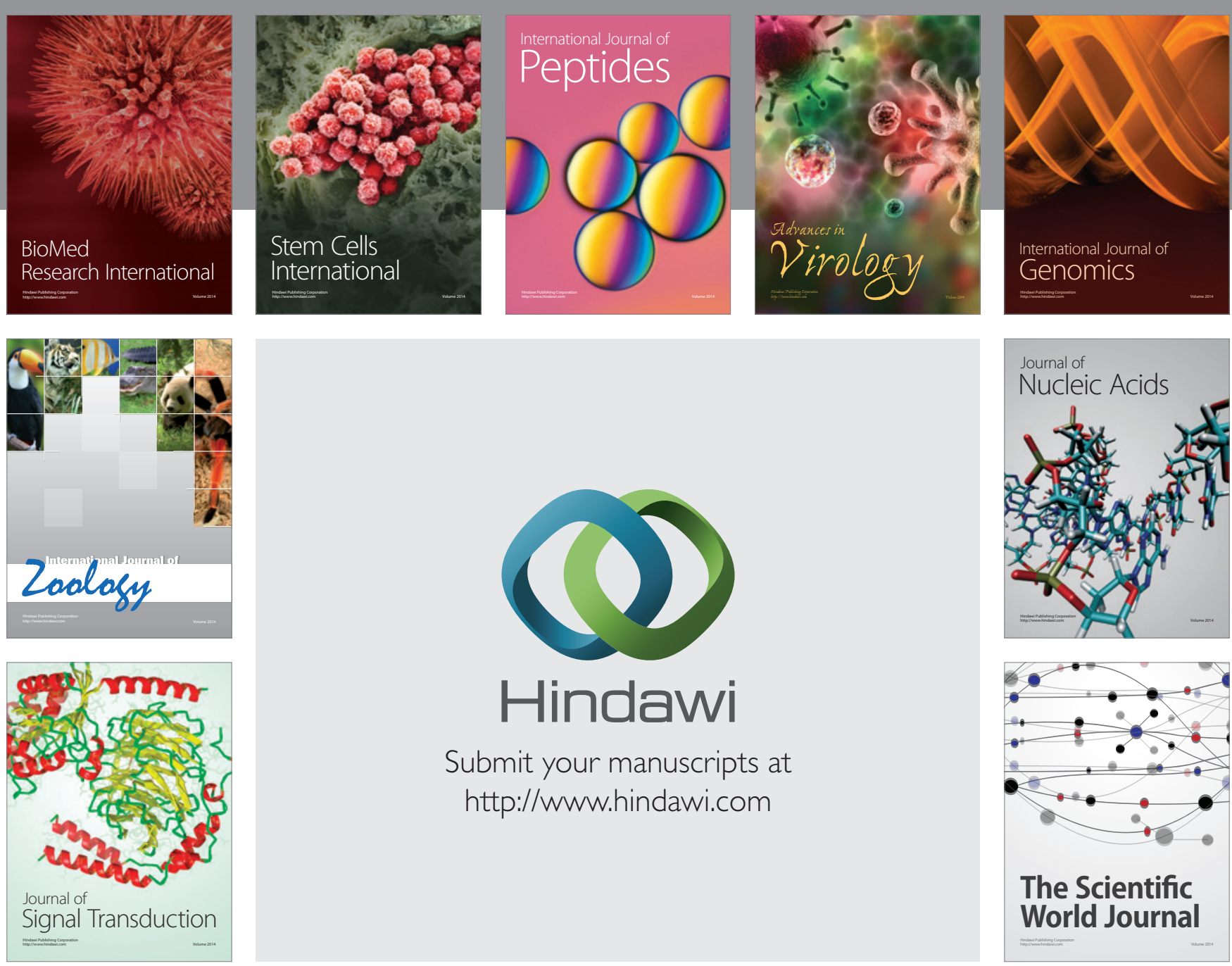

Submit your manuscripts at

http://www.hindawi.com
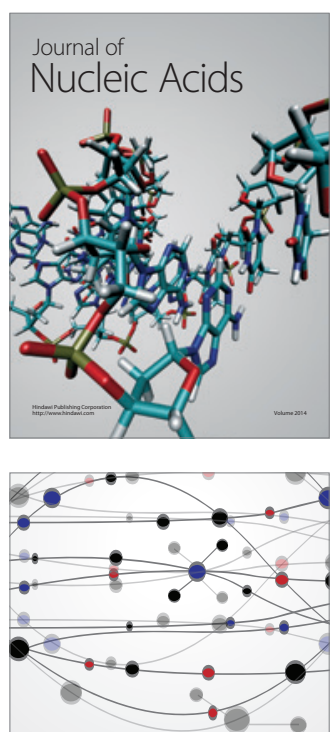

The Scientific World Journal
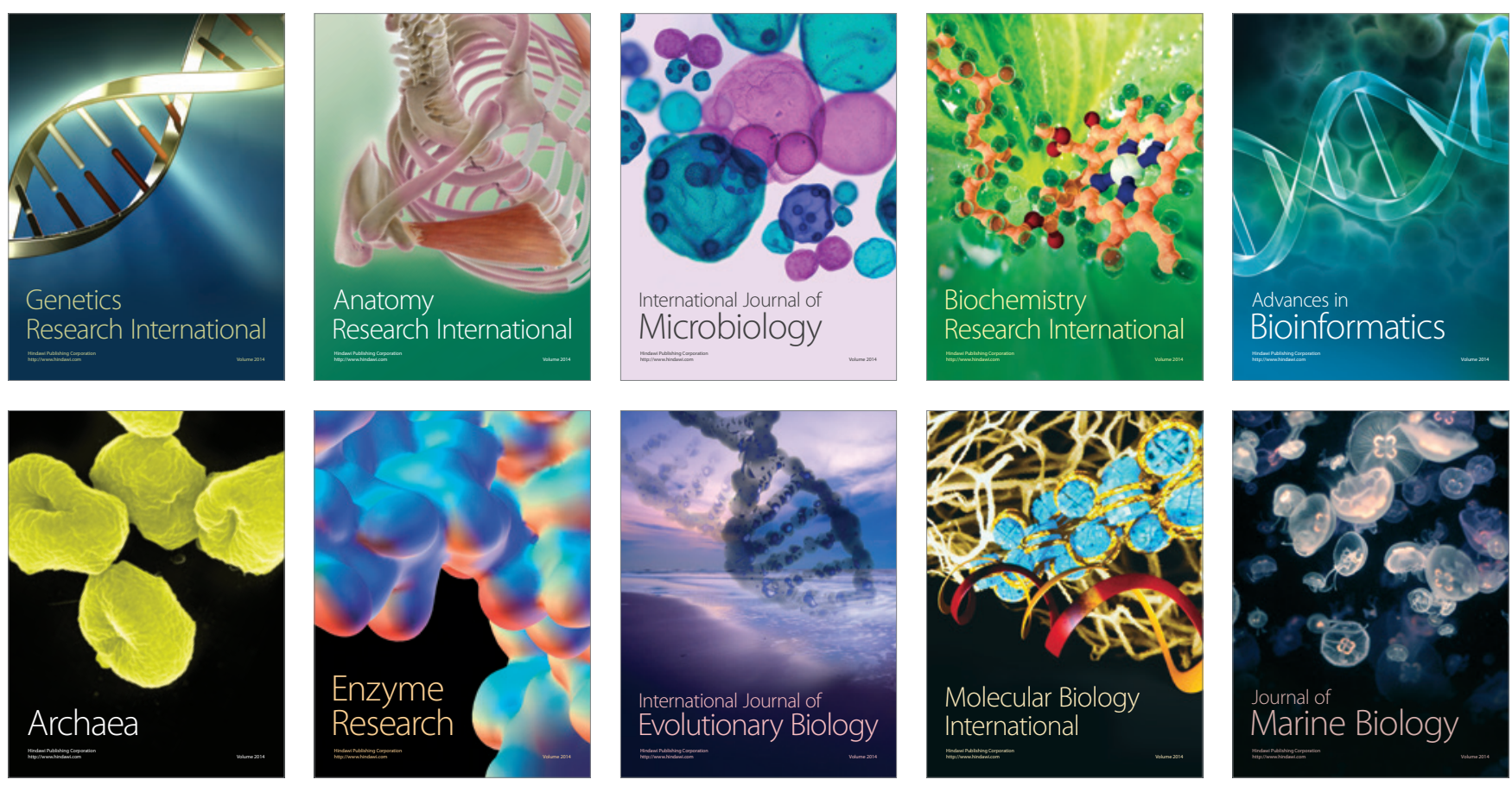